\title{
Enfrentando a evasão universitária: o caso do projeto tutorias no curso de Zootecnia
}

\author{
Nádia Velleda Caldas ${ }^{1}$ \\ Flávio Sacco dos Anjos ${ }^{2}$
}

\begin{abstract}
RESUMO
O sistema de ensino superior no Brasil se ampliou e se complexificou ao longo das três últimas décadas. Não obstante, no aludido período a evasão e o abandono têm sido uma constante tanto no âmbito das instituições públicas como privadas. Em boa medida a evasão escolar, em seus diversos níveis, acaba por alimentar a perversa dinâmica dos jovens que não estudam nem trabalham (fenômeno "nem-nem") que incide no Brasil e em diversos países do planeta. $\mathrm{O}$ foco do presente artigo se insere no âmbito das pesquisas relacionadas com a evasão no ensino superior. Nesse estudo analisamos os dados de investigação realizada em uma universidade pública do sul do Brasil e dentro de um curso específico (Zootecnia), onde foi levado a efeito uma iniciativa concreta de enfrentamento às altas taxas de evasão. A filosofia do projeto se assentava no esforço por criar uma atmosfera de acolhimento para os alunos ingressantes, instituindo a figura do professor tutor e do aluno madrinha ou padrinho. Os dados mostram uma avaliação positiva por parte do público-alvo do projeto, bem como a geração de informações que visam aperfeiçoar o seu funcionamento.
\end{abstract}

Palavras-chave: evasão; abandono; avaliação; zootecnia.

\section{Facing university evasion: the case of the tutories project in the Zootechny course}

\begin{abstract}
The higher education system in Brazil has expanded and become more complex over the past three decades. However, in the period mentioned, evasion and abandonment have been a constant in both public and private institutions. To a large extent, school dropout, at its various levels, ends up feeding the perverse dynamics of young people who neither study nor work ("neither study nor work" phenomenon) that affects Brazil and in several countries on the planet. The focus of this article falls within the scope of research related to dropout in higher education. In this study, we analyzed the research data carried out at a public university in southern Brazil and within a specific course (Zootechnics) where a concrete initiative to tackle the high dropout rates was carried out. The philosophy of the project was based on the effort to create a welcoming atmosphere for incoming students, establishing the figure of the tutor teacher and the godmother or godfather student. The data shows a positive evaluation by the target audience of the project, as well as the generation of information that aims to improve its functioning.
\end{abstract}

Key words: evasion; abandonment; evaluation; zootechnics

\section{INTRODUÇÃO}

É deveras preocupante o quadro desenhado a partir das informações advindas da Pesquisa Nacional por Amostra de Domicílios Contínua (PNAD, 2020), realizada anualmente pelo Instituto Brasileiro de Geografia e Estatística (IBGE), do ponto de vista da ocupação da população brasileira, sobretudo no que tange à situação dos mais jovens. Estamos diante do que vulgarmente se conhece como fenômeno "nem-nem", o qual alude ao crescimento de um segmento de nossa juventude que não frequenta nenhum tipo de escola, bem como não exerce qualquer tipo atividade laboral.

\footnotetext{
${ }^{1}$ Doutora em Agronomia, Professora Associada do Departamento de Ciências Sociais Agrárias/FAEM/UFPel e Docente permanente do Programa de Pós-graduação em Sistemas deProdução Agrícola Familiar

${ }^{2}$ Doutor em Sociologia, Professor Titular do Departamento de Ciências Sociais Agrárias.
} 
Segundo a fonte citada, dentro da faixa etária compreendida entre 20 e 24 anos a proporção de "nem-nem", que já era alta, passou de $28,6 \%$ no último trimestre de 2009 para 35,2\% no segundo trimestre de 2020 (IBGE, 2020). Trata-se de um máximo histórico desde que o IBGE passou a desenvolver esse tipo de levantamento.

No caso europeu esse fenômeno não é novo, além de ser recorrente entre as diversas nações, ainda que com distintos graus de incidência. Estatísticas recentes (EUROSTAT, 2020) indicam que em 2018, na faixa etária compreendida entre 20 e 34 anos, o fenômeno "nem-nem" se destaca em países como: Macedônia (36,3\%), Turquia (33,2\%), Itália (28,9\%), Montenegro (27,5\%), Grécia (26,8\%), Sérvia (24,1\%), Bulgária (20,9\%), Romênia (20,6\%), Eslováquia (20,0\%), Espanha (19,6\%), Croácia (18,5\%) e França (17,7\%). A média dos 28 países integrantes da União Europeia equivale a 16,5\%.

Tudo indica que a pandemia do Covid-19 possa haver agravado ainda mais tal situação. No caso brasileiro esse fato cobra importância não somente por alcançar uma proporção alarmante, mas especialmente em virtude dos desdobramentos que acarreta. Há uma tendência de que boa parte dos jovens, sobretudo dos que vivem em periferias e bairros pobres, acabe sendo arregimentada pelas milícias urbanas e pelos traficantes de estupefacientes. A crise de perspectivas atravessa os mais diversos âmbitos da vida social brasileira, incluindo, obviamente, a esfera universitária, seja ela de caráter público ou privado. A evasão no ensino superior, de que tratará esse artigo científico, é uma das facetas através das quais esse quadro se manifesta, realimentando a mesma dinâmica.

Os dados do último Censo da Educação Superior no Brasil (2018) revelam certas tendências que se consolidam ao longo da década. A primeira delas aponta uma sensível expansão do ensino superior (presencial e não-presencial). Isso fica evidenciado a partir de números relativos à quantidade de alunos que ingressaram nos cursos de graduação entre os anos 2008 e 2018, a qual sofreu um incremento da ordem de aproximadamente $47,5 \%$. A segunda tendência, a partir dos mesmos dados, reveste igual importância, a qual reflete um crescimento na participação do ensino privado em relação ao público. Em 2008 a participação do regime privado equivalia a aproximadamente $77 \%$, ao passo que em 2018 ela ascendia a $83,1 \%$. O fato é que no mesmo período a expansão do ensino público, em termos de número de ingressos, se elevou apenas $7,9 \%$, enquanto a rede privada experimenta uma expansão da ordem de $59,3 \%$ para o mesmo período.

A terceira tendência é o crescimento substancial na proporção de ingressos no ensino à distância. Eis que em 2008 essa modalidade de ensino correspondia a 463.093 ingressos na graduação, ao passo que no final da década o mesmo número ascende a 1.373.321. Em termos relativos passamos de escassos 19,8\% para $40 \%$. Mas esse aumento se explica, basicamente, a partir do incremento da proporção do regime privado. Isso porque, entre 2017 e 2018, houve uma retração $(1,5 \%)$ da rede federal, da ordem de 34.763 vagas oferecidas nos cursos à distância, ao passo que na rede privada a situação se mostrou clara e diametralmente na direção oposta.

Em termos globais, o número de matrículas no ensino superior (presencial e à distância) experimentou um crescimento ininterrupto ao longo da última década, equivalente a aproximadamente 44,6\%, passando de 5.843 .322 em 2008 para 8.451.748 em 2018 . Comparativamente esse montante supera a população atual de países como Bulgária, Sérvia, Dinamarca, Finlândia, Eslováquia, Noruega ou Irlanda, apenas para citar alguns exemplos. Mas é claro que os números do ensino superior no Brasil refletem as dimensões de um país continental e não podem ser tomados fora de seu contexto.

Dados do último censo demográfico (IBGE, 2010) já apontavam que o número de brasileiros com diploma universitário havia crescido 7,9\%, um percentual bastante mais alto que o incremento constatado na década anterior correspondente a 4,4\%. Mas as fontes 
estatísticas trazem também números desconcertantes, tal como o fato de que $52,6 \%$ dos brasileiros com mais de 25 anos de idade ainda não concluíram sequer a educação básica (ensino médio), sendo que destes, 33,1\% não terminaram nem mesmo o ensino fundamental, como assim informa a Pesquisa Nacional por Amostra Contínua (PNAD, 2018).

Ainda segundo a mesma fonte, 11,3 milhões de pessoas de 15 anos e mais são analfabetas $(6,8 \%$ do total), índice que ilustra a gravidade do quadro educacional brasileiro. Frente a estes números surgem os mais diversos tipos de posicionamentos no âmbito político e institucional. Dentro de um cenário de retração do gasto público em educação, por razões que escapam ao objeto deste artigo, algumas vozes defendem a gradual retirada dos investimentos no ensino superior e sua destinação para a educação básica e o combate ao analfabetismo.

Não é preciso muito esforço para contrapor um tipo de argumento tecido a partir de uma brutal simplificação da realidade. Em meio aos debates sobre o estado da educação no Brasil, volta à cena uma conhecida frase enunciada por Darci Ribeiro, um dos mais célebres intelectuais brasileiros no começo dos anos 1980. Eis que em tom absolutamente profético durante apresentação de uma conferência afirmou: "se os governantes não construírem escolas, em 20 anos faltará dinheiro para construir presídios".

Parece claro que o enfrentamento às mazelas da educação brasileira não pode ocorrer a partir de uma operação aritmética de transferência de recursos do âmbito do ensino superior para o nível fundamental. Experiências internacionais promissoras mostram que o desenvolvimento dos países só pode ocorrer a partir de investimentos substanciais na formação de recursos humanos em seus diversos níveis, assim como na inovação científica e tecnológica e na produção do conhecimento.

Entrementes, a expansão das fontes de financiamento e a ampliação dos mecanismos de sustentação material da educação em geral não podem ocorrer de costas para o necessário aperfeiçoamento dos sistemas de avaliação e monitoramento. No caso das universidades brasileiras existem, nesse plano, diversos instrumentos de mensuração da eficiência dos processos de formação de recursos humanos.

Esse é o caso da taxa de titulação, entendida como a razão entre o número de alunos concluintes e o número total de alunos matriculados, dentro do período normal ou aceitável de integralização de um determinado curso de nível superior. Tomada em seu sentido amplo a taxa de titulação espelha a capacidade dos ingressantes de finalizar um processo de formação e de dotar os indivíduos de condições para ingressar no mercado de trabalho e/ou de converteremse em sujeitos dos próprios destinos.

Não obstante, são recorrentes os casos de cursos onde a taxa de titulação está muito aquém do esperado. A grande evasão e abandono estudantil responde a um feixe muito amplo de causas e circunstâncias que merecem ser abordadas. Esta é a primeira premissa de que partimos ao elaborar esse artigo. A segunda premissa é no sentido de desenhar estratégias que permitam enfrentar um quadro que se mostra desafiador diante nas implicações que esse assunto adquire nas atuais circunstâncias. A terceira e última premissa é que experiências dessa natureza devem ser compartilhadas e, dentro do possível, lapidadas e replicadas em outras latitudes.

Este artigo apresenta e discute uma iniciativa concreta de redução da evasão escolar dentro de um curso específico pertencente a uma instituição federal de ensino superior Universidade Federal de Pelotas - situada no sul do Brasil. Nesse contexto, caberia indagar: como se apresentava a evasão à época da implantação do projeto? Que medidas foram adotadas e que resultados puderam ser colhidos após a sua implantação? São estas as grandes questões que se busca desenvolver nesse artigo. O trabalho integra, além dessa breve introdução, quatro outras seções. A primeira delas aborda a questão da evasão enquanto objeto da reflexão científica. A segunda descreve e analisa o contexto da pesquisa, enfatizando os dados de que partimos ao levar a cabo essa iniciativa. É na terceira seção onde a metodologia adotada é 
exposta, assim como os resultados alcançados. A quarta e última seção reúne as considerações finais de um estudo relativo a um contexto em constante estado de mutação. Não temos a pretensão de indicar resultados conclusivos, muito menos de esgotar um tema reconhecidamente multifacetado e complexo.

\section{A EVASÃO ESCOLAR COMO OBJETO DE ESTUDO}

Não cabe dúvida de que o sistema universitário brasileiro se expandiu e se complexificou nas duas últimas décadas, sendo que as três grandes tendências enunciadas anteriormente são apenas algumas das facetas desse processo. É nesse contexto que a questão da evasão cobra relevância, não somente pela dimensão que sua incidência assume para o sistema universitário, mas especialmente em virtude dos custos que acarreta para o país e para as diversas instituições de ensino superior.

Trata-se de fenômeno complexo, como bem destacam diversos estudos (DIOGO et al, 2016; BAGGI; LOPES, 2011; CUNHA; SCALI, 2009; CARRILHO, 2005) e que responde aos mais diversos tipos de causas e circunstâncias. A definição é parte da complexidade diante das variações conceituais encontradas na literatura geral e especializada que aborda o assunto. Diante desse fato surgem dificuldades que impedem avançar no estudo deste fenômeno, sobretudo no que tange a estabelecer comparações no tempo e no espaço, bem como no sentido de acarretar interpretações equivocadas (VELLOSO; CARDOSO, 2008).

Estudo realizado por Mazzeto, Bravo e Carneiro (2002, p. 1205) define a evasão como sendo "[...] toda e qualquer forma de saída do estudante do curso que não tenha sido pela diplomação". Vanz et al (2016, p.546), em pesquisa realizada junto ao curso de Biblioteconomia da Universidade Federal do Rio Grande do Sul (UFRGS) consideraram evadidos:

[...] os alunos que se encontravam desligados do curso, por diferentes motivos: desligamento por abandono, afastamento por trancamento, desistência de vaga, jubilamento, transferência interna, transferência para outra universidade e falecimento.

Ou seja, nesse caso fica claro que tais autores consideram evasão como um conceito abrangente, englobando as mais diversas situações que surgem no cotidiano das faculdades, institutos e universidades do país. Desse modo, toda e qualquer interrupção na trajetória acadêmica é considerada evasão universitária, seja ela em caráter temporário ou permanente. Em 1995 o Ministério da Educação instituiu uma Comissão Especial para o estudo da evasão do ponto de vista de suas causas, bem como para estabelecer instrumentos de enfrentamento a esse problema. No documento por ela elaborado a evasão apresenta três modalidades, a evasão do curso, da instituição e do sistema. Nesses termos,

Evasão de curso: quando o estudante desliga-se do curso superior em situações diversas tais como: abandono (deixa de matricular-se), desistência (oficial), transferência ou reopção (mudança de curso), exclusão por norma institucional; evasão da instituição: quando o estudante desliga-se da instituição na qual está matriculado; evasão do sistema: quando o estudante abandona de forma definitiva ou temporária o ensino superior (BRASIL, 1997, p. 20).

De toda sorte, a imprecisão conceitual se vê traduzida no fato de que algumas instituições consideram a evasão no sentido amplo, ao passo que outras adotam distinto entendimento, como por exemplo, o de não considerar como tal as situações em que o aluno muda de curso, mas permanecendo na mesma universidade ou faculdade, como assim adverte Lobo (2012, p.8) em seu estudo. 
Outro aspecto que sobressai nos estudos sobre evasão é o intento de investigar as circunstâncias da evasão. Nesse sentido, coincidimos com outros estudos (VANZ et al, 2006; BARDAGI; HUTZ, 2009) que admitem tratar-se de uma dinâmica que se impõe, na maioria das vezes, nas fases iniciais de um dado curso universitário.

Outro aspecto sobre o qual existe grande convergência é com relação aos prejuízos engendrados pela evasão, seja do ponto de vista das instituições públicas, seja do ponto de vista das instituições privadas. Em boa medida, a sociedade como um todo se vê afetada por conta da interrupção de um processo de formação, do desperdício de recursos e da frustração que promove na vida dos indivíduos e das famílias que, ao longo de gerações, ansiavam contar com seus membros como detentores de um diploma de nível superior.

O conteúdo simbólico dessa conquista vai muito além das estatísticas dentro de um país que tem como uma de suas marcas insofismáveis a desigualdade e a exclusão social. Ainda que a conclusão de um curso superior não garanta uma entrada segura no mundo do trabalho, não cabe dúvida de que a universidade representa uma estrutura de ascensão social para as classes menos favorecidas.

A aludida expansão do sistema universitário brasileiro está diretamente ligada a programas criados pelo Estado, especialmente a partir última década. Foi assim durante os dois sucessivos mandatos do presidente Lula (2003-2010) através do Programa de Apoio a Planos de Reestruturação e Expansão das Universidades Federais (REUNI) que ampliou sensivelmente o número de vagas nas universidades públicas, seja no caso de cursos existentes e oferta de cursos noturnos, seja mediante a criação de novas faculdades e institutos federais.

O mesmo há que ser dito em relação ao Programa Universidade para Todos (PROUNI), responsável por conceder bolsas de estudo integrais e parciais a cursos de Graduação e sequenciais de formação específica. Tal esforço incluiu ainda o caso da Universidade Aberta do Brasil (UAB), sistema integrado por universidades públicas cuja vocação precípua é oferecer cursos de nível superior à distância para segmentos da população que apresentam dificuldade de acesso à formação universitária.

Como bem destacaram Diogo et al (2016, p.129), o REUNI “[...] é um dos primeiros programas governamentais que, especificamente, busca combater a evasão escolar por intermédio da implementação de apoio pedagógico aos estudantes de graduação nas IES federais". A implementação de ações afirmativas pressupunha facilitar o acesso de pessoas negras e pardas aos bancos universitários, coroando uma orientação claramente voltada à correção de injustiças que remontam a tempos muito distantes. Através da Portaria $\mathrm{n}^{\circ} 39$ do Ministério da Educação é criado o Programa Nacional de Assistência Estudantil (PNAES), o qual tem por desiderato, promover a inclusão social, democratizar as condições de permanência dos estudantes matriculados em cursos de graduação presencial das Instituições Federais de Ensino Superior (IFES) e reduzir as taxas de retenção e evasão (BRASIL, 2007)

Convergimos inteiramente com autores (ANDRIOLA; ANDRIOLA; MOURA, 2006; SAMPAIO et al., 2011) que apontam os desperdícios causados pela evasão, a qual está associada à elevação de custos e a vagas ociosas nas instituições federais de ensino superior. Entretanto, não se trata de uma questão cingida apenas ao âmbito público, dado que atinge também as instituições privadas que igualmente são financiadas através das arcas do Estado. Ao fim e ao cabo, recursos escassos são vítimas do desperdício.

Conforme Sampaio et al. (2011), trata-se de uma questão que ainda é pouco estudada no contexto brasileiro, razão pela qual torna-se crucial examinar suas causas, bem como propor iniciativas que atenuem os seus efeitos dentro de um país de dimensões continentais. Do ponto de vista das suas causas, existe uma ampla controvérsia, a qual seria impossível restituir no espaço que aqui dispomos. 
Segundo estudo realizado por Diogo et al (2016, p.130), apoiado em outro trabalho (DIAS et al., 2006):

De maneira geral, é possível identificar dois grupos de fatores relacionados ao fenômeno: os externos à instituição, como vocação, aspectos socioeconômicos e problemas de ordem pessoal dos alunos; e os internos à instituição, como infraestrutura da IES, corpo docente e assistência sócio-educacional (destacado no original).

No âmbito dos fatores externos à instituição merece destaque a situação econômica que atravessa o país. Não é necessário muito esforço para entender que o entusiasmo pelo ingresso na vida universitária - não raras vezes - se converte bruscamente em frustração, quando o discente se vê diante da contingência de renunciar aos estudos para lutar pela própria sobrevivência e/ou para garantir a sustentação material da família. É certo que a assistência estudantil tornou-se uma peça chave para assegurar a permanência de alunos de baixa renda, seja pelo acesso a uma alimentação subsidiada, seja pelo financiamento parcial ou integral da moradia.

Não deve ser visto como irrelevante o fato de que, pela primeira vez na história do Brasil, a percentagem $(50,3 \%)$ de pretos e pardos no ensino superior público supera a proporção de brancos. Nesse contexto, os dados da PNAD contínua (IBGE,2018) revestem importância na medida que indicam uma "revolução silenciosa" que vem sendo operada desde a implantação das ações afirmativas no âmbito do Sistema de Seleção Unificada (SISU). A universidade pública converteu-se no cenário de uma mudança sem precedentes.

Não obstante, a evasão é um tema deveras preocupante. Com efeito, estamos plenamente de acordo com Diogo et al (2016, p.133) quando afirma que "[...] tradicionalmente a evasão universitária é debitada na conta do estudante, compreendida como consequência de base educacional insuficiente do aluno para acompanhar o curso". A incapacidade de lidar com a questão está inextricavelmente ligada ao imobilismo de investigar suas causas e de promover ações efetivas para que seja, ao menos, minimizada. No caso das instituições privadas a taxa de evasão funciona como uma publicidade negativa para eventuais interessados em ingressar em um determinado curso ou faculdade.

Para os objetivos que persegue este artigo nos interessa sublinhar o que Vanz et al (2016) chamam de "falta de informação sobre o curso" em que o aluno ingressa. Já vimos que a evasão tende a acontecer nas fases iniciais, mas certamente o desconhecimento sobre a natureza de um determinado campo de estudos parece jogar um peso considerável. O estudo citado elegeu como objeto de estudo o curso de Biblioteconomia da UFRGS, que, para muitos alunos, era visto como segunda opção para os alunos ingressantes. Entre as conclusões de Vanz et al (2016, p.565), consta o que se segue:

Observou-se que a iniciativa para desistir e de fato, a desistência, acontece logo no início do curso, especialmente no primeiro semestre. Neste sentido, a coordenação do curso pode procurar desenvolver um trabalho motivacional e de informação sobre o curso e a carreira profissional com alunos do primeiro e segundo semestres.

Parte-se aqui do entendimento de que reduzir a retenção nas faculdades e ampliar as taxas de titulação não requer recursos de monta ou de ações que impeçam o andamento normal das lides universitárias. A experiência que se busca descrever nesse artigo aponta justamente nessa direção. Num mundo onde nunca dantes fluiu tanta informação torna-se inaceitável que as pessoas que anseiam um diploma universitário não tenham acesso a conhecimentos básicos sobre o que lhes espera ao longo do curso em que ingressaram.

Mas a questão da desinformação não pode ser vista como dissociada de outros problemas ou fatores. A frustração experimentada por muitos jovens transcende essa questão. $\mathrm{O}$ ambiente universitário pode ser fascinante para muitos ingressantes, mas também um terreno 
sombrio onde impera a lei da meritocracia e da competição individual. À época em que concebemos o projeto que ensejou esse artigo científico fomos surpreendidos pela morte brutal de estudante da Fundação Universidade do Rio Grande (FURG), instituição federal de ensino superior situada na cidade do Rio Grande, extremo sul do Brasil. O sentimento de estupefação não surgiu apenas do fato de ser o suicídio de um jovem paulista de apenas 22 anos, mas por se tratar de um estudante exemplar do ponto de vista do desempenho acadêmico no curso de engenharia mecânica naval. A matéria amplamente noticiada na imprensa regional e nacional apontava como possíveis causas a ansiedade do discente em encontrar um estágio profissional.

Não temos aqui a pretensão de debater acerca de um tema tão sensível e complexo. O que nos parece claro é que o caso em questão não é uma situação isolada, muito menos o resultado de causas que afetam o que se passa exclusivamente dentro das fronteiras da universidade. Estudo realizado por Andrade e Teixeira (2017) exalta a importância da dimensão psicossocial como expressão de uma nova vertente dentro dos estudos que se voltam às causas da evasão universitária. Como bem sublinham estes autores, a assistência estudantil vai muito além das questões ligadas à alimentação e moradia estudantil. Andrade e Teixeira (2017), com base em outro estudo (BARDAGI; ANDRADE; TEIXEIRA, 2010, p.514) resumem o entendimento sobre o rumo atual da política nacional de assistência estudantil no que tange ao combate à evasão universitária:

A partir das últimas décadas vêm sendo desenvolvidos estudos para identificar os efeitos que as vivências universitárias têm sobre o desenvolvimento dos discentes, sobre o seu desempenho acadêmico e sua adaptação à universidade, mas a preocupação com o estudante universitário - para além do assistencialismo - é ainda recente, especialmente em termos de serviços de apoio e orientação (grifos nossos).

O ambiente universitário deveria converter-se num espaço de construção de dinâmicas que fortalecessem laços de cooperação, de práticas de solidariedade, de enfrentamento aos vários tipos de preconceito (racial, gênero, social, religioso, etc.) e formas de discriminação. Mas a realidade demonstra que se trata de um processo sinuoso e extremamente difícil para o qual inexistem fórmulas, modelos ou receitas milagrosas. A evasão representa a face visível de fatores e circunstâncias extremamente complexas, o que não nos exime do compromisso de usar a criatividade e o bom senso para conceber novas estratégias e caminhos de superação. Esse é o foco da próxima seção, a qual apresenta e discute a trajetória do projeto "Tutorias na Zootecnia", ligado à Faculdade de Agronomia da Universidade Federal de Pelotas.

\section{O PROJETO TUTORIAS NO CURSO DE ZOOTECNIA}

Com seus mais de meio século de existência a Universidade Federal de Pelotas é uma instituição situada no interior do Rio Grande do Sul que exerce protagonismo no que tange à formação de recursos humanos, produção do conhecimento, extensão e prestação de serviços em sua área de influência. A comunidade, por ela representada, integra um contingente equivalente a 23.614 pessoas, incluindo estudantes de graduação em nível presencial (16.461), à distância (1.763), doutorado (1.034), Mestrado (1.284) e especialização (285), bem como de docentes (1.455) e servidores técnico-administrativos (1.332).

Nesse contexto, a Faculdade de Agronomia representa uma de suas mais tradicionais unidades acadêmicas. Em seu interior funcionam atualmente dois cursos de graduação (Agronomia e Zootecnia) e oito (08) programas de pós-graduação stricto sensu. Todavia, um olhar retrospectivo para os últimos cinco anos indica uma realidade bastante preocupante. Referimo-nos ao fato de que há uma sensível elevação nas taxas de evasão estudantil. Diversas são as razões apontadas para esse fato. Algumas delas são de caráter estrutural, envolvendo a

Revista Desenvolvimento Socioeconômico em debate v.7 n.1 (2021) 
precária formação dos alunos que ingressam hoje na universidade brasileira em termos de conhecimentos básicos, especialmente na área da matemática, física e química.

A fase inicial (básico) é justamente o momento onde tais dificuldades se exacerbam, fazendo com que expressiva parcela do alunado acabe desistindo de cursar a faculdade, sem que ao menos tenha vivenciado o período profissionalizante, que é justamente o momento em que se afirmam as bases para o exercício profissional e se consolidam os fundamentos da formação acadêmica e científica. Seguramente é esta a etapa mais apaixonante em virtude de serem ministrados conhecimentos de caráter aplicado, tanto os de natureza geral como específica.

Dentre os dois cursos ministrados (Agronomia e Zootecnia) é no segundo deles onde se encontram as mais altas taxas de abandono. Â época em que o projeto Tutorias foi implantado o curso de Zootecnia completava dez anos de existência. Se levamos em conta o total de estudantes ingressantes, descontados os cancelamentos, chegaremos a um montante equivalente, até os dias atuais, a 618 alunos. Todavia, no mesmo período, foram contabilizados, em termos absolutos, 179 abandonos de curso. Quando se toma por base o primeiro semestre de 2014 chegaremos a um índice de abandono equivalente a quase $47 \%$ do total de ingressantes que deveriam titular-se em 2018.

No já citado estudo realizado por Diogo et al (2016) o curso de Zootecnia é mencionado como o primeiro dos dez cursos com maiores taxas de evasão de uma outra Universidade pública (Universidade Federal de Santa Catarina) situada no Sul do Brasil, de modo que o caso em epígrafe não pode ser visto como uma novidade. Lobo et al (2007), analisando dados oficiais relativos às diversas instituições de nível superior, concluiu: "Com exceção do resultado do curso de Zootecnia, em 2001, todos os cursos da área de Agricultura e Veterinária e a própria área como um todo tiveram, no período, uma evasão anual menor que a média nacional”.

Vale frisar que Davok e Bernard (2016), em estudo realizado junto à Universidade do Estado de Santa Catarina (UDESC), analisam a evasão no triênio (2008-2009-2010), concluindo que o curso de Zootecnia apresentou taxas muito elevadas, equivalentes a respectivamente $63,1 \% ; 55,1 \%$ e $48,9 \%$, muito acima do constatado na área das Ciências Agrárias como um todo, que equivalem a respectivamente $32,0 \% ; 37,5 \%$ e $24,9 \%$ no mesmo período.

Depoimentos colhidos informalmente junto a alunos, professores e servidores técnicoadministrativos sinalizavam no entendimento de que boa parte dos discentes via a Zootecnia como a segunda opção, dado que a primeira delas era o curso de Veterinária. Sendo ainda mais pragmáticos, para estes indivíduos a Zootecnia seria como uma espécie de "curso de passagem", tendo em vista o interesse em migrar para a Veterinária. Ficando na Zootecnia não estariam totalmente parados enquanto se preparavam para uma nova tentativa de ingresso na Veterinária. Configura-se, assim, uma situação típica de desperdício de energias e de recursos públicos na medida em que a taxa de titulação (43\%), dentro do prazo regular, acaba ficando muito aquém do desejável.

Para além dos argumentos contrários a esse tipo de dinâmica, construída a partir do ponto de vista dos estudantes ingressantes na Zootecnia, havia claramente o reconhecimento de que algo deveria ser feito para mudar essa realidade. Esse foi o espírito que norteou as diversas reuniões de trabalho realizadas pelos docentes, as quais ensejaram a criação do projeto Tutorias. Partiu-se do pressuposto de que ações concretas poderiam, ao menos, reduzir os indicadores aludidos anteriormente. O projeto Tutorias busca implicar os docentes no enfrentamento aos elevados índices de abandono a partir da criação de espaços informais de interação, fortalecendo a relação educador-educando, bem como no intuito de criar um instrumento de interlocução direta entre estudantes recém-ingressados e os docentes da FAEM, os quais, livre e voluntariamente, decidam participar do processo. 
Dentre os objetivos constava: a) criação de um canal de interação direta entre educadores e educandos do curso de Zootecnia da UFPel; b) fortalecer a relação entre discentes e docentes pela via do diálogo e do compartilhamento de informações; c) propiciar uma melhor integração dos alunos ingressantes ao curso de Zootecnia e às estruturas de ensino da UFPel como um todo; d) facilitar informações relativas aos grupos de pesquisa em funcionamento dentro da própria FAEM para que os discentes ingressantes possam se identificar com temas de interesse e futuros campos de atuação e e) contribuir ao processo de formação técnica e humana dos discentes pela via da necessária conciliação da dimensão social e da dimensão psicológica que permeiam o processo de ensino-aprendizagem.

A metodologia propunha o estabelecimento de uma dinâmica de encontros regulares (quinzenais), ao longo do primeiro e do segundo semestre de ingresso do discente matriculado no curso de Zootecnia com o seu/sua respectivo (a) professor (a) tutor (a). Tais encontros seriam realizados nas salas dos professores tutores ou em local a ser definido, cujo objetivo é estabelecer uma via de comunicação direta, facilitando informações de caráter geral e específico acerca do curso, da própria universidade, da cidade, etc. Institui-se, assim, a figura do professor Tutor, mas também a de alunos padrinhos e madrinhas, quais sejam, estudantes "veteranos" voluntariamente encarregados de passar informações aos calouros e auxiliar os docentes tutores nas reuniões com seus tutorados. A ênfase sempre recaiu no sentido de propor formas efetivas de combater o isolamento dos discentes, facilitar informações, reduzir problemas de aprendizagem, atenuar tensões internas à FAEM, minimizar ou equacionar eventuais conflitos.

Os docentes dispostos a se integrar ao projeto deveriam ter envolvimento efetivo com o curso de Zootecnia, disponibilidade para que os encontros com tutorados se desenvolvessem de forma satisfatória, interesse em compartilhar informações e experiências, ter empatia com os objetivos do projeto e com a filosofia que permeava suas ações, bem como disposição ao diálogo e à comunicação.

\section{PROCEDIMENTOS METODOLÓGICOS}

Os dados que serão aqui apresentados se inserem dentro do esforço de reunir informações que permitam avaliar os alcances do projeto a partir do prisma dos próprios alunos que dele participaram como público-alvo. Ou seja, para além dos registros dos docentes, alunos padrinhos e madrinhas envolvidos, o ponto crucial era saber o que pensavam os discentes beneficiários. Tais estudantes, além dos encontros periódicos com os tutores, estiveram implicados, em maior ou menor medida, em ações de integração realizadas pelos envolvidos.

Ingressam semestralmente 40 alunos no curso de Zootecnia. Não obstante, à época da realização da pesquisa estavam efetivamente matriculados e frequentando as aulas 35 discentes. A todos estes alunos foi enviado, através da coordenação do curso, um formulário eletrônico contendo 16 questões que intercalavam perguntas fechadas, mas também questões abertas. Desse modo, tem-se que, do universo de alunos participantes da pesquisa, tivemos uma proporção de respondentes efetivos equivalente a $57,1 \%$.

Adotamos, portanto, uma orientação não-probabilística em meio a uma amostragem por acessibilidade ou conveniência, a qual se caracteriza por selecionar os elementos a que se tem acesso (GIL, 2007). O que alguns poderiam denominar de um número reduzido de respondentes se vê atenuado pelo fato de que são estes os sujeitos do processo, bem como o foco sobre o qual nossas atenções estavam dirigidas. Desse modo, da totalidade de alunos que voluntariamente aderiram ao projeto, uma maioria expressiva aceitou dedicar seu tempo em responder as questões, enunciar críticas, bem como sugerir formas de aperfeiçoamento do projeto Tutorias. Ao enviar o formulário eletrônico reiteramos o compromisso de garantir o anonimato em

Revista Desenvolvimento Socioeconômico em debate v.7 n.1 (2021) 
relação às informações colhidas. Os dados que serão aqui apresentados e discutidos foram compilados e analisados através do uso do Excel.

\section{RESULTADOS DA PESQUISA}

Os discentes tutorados tomaram contato com o projeto Tutorias das mais diversas formas. Não obstante, todos manifestaram que conheciam a filosofia e objetivo do projeto. Para aferir esse entendimento pedimos que estes indicassem, com suas próprias palavras, quais seriam os principais objetivos do projeto, segundo sua própria acepção. Em relação a esse aspecto, nada menos que $45 \%$ centraram suas respostas na questão do combate à evasão/abandono/desistência. Alguns depoimentos são interessantes na medida em que agregam outros temas sobre os quais a atenção deveria estar posta. Segundo um dos discentes entrevistados, o objetivo central do projeto é: "Ajudar os alunos ingressantes a conhecer melhor o curso e diminuir a desistência".

Quando perguntados se haviam se envolvido em algum tipo de atividade atinente ao projeto, $100 \%$ responderam afirmativamente. Ao serem perguntados sobre a realização de reuniões periódicas com o professor Tutor, $80 \%$ responderam que sim. Os que responderam de forma negativa indicaram como motivos a falta de oportunidade e o desinteresse ou indisponibilidade do docente tutor.

Indagamos os discentes acerca do número de encontros com o professor Tutor. Em relação a esse aspecto, 12,5\% reuniram-se uma única vez, 6,3\% duas vezes e $25 \%$ três vezes. Nada menos que 56,2\% correspondem aos alunos que se reuniram quatro ou mais vezes, sendo esse o coletivo onde marcadamente a interação foi bastante efetiva, não somente em termos da relação tutor-tutorado, mas também de ações que tiveram a mediação dos padrinhos e madrinhas. Esse dado aparece claramente evidenciado no fato de que $100 \%$ dos respondentes se reuniram com o aluno ou aluna veterana (padrinho ou madrinha). Dentro desse grupo, 55\% dos alunos se reuniram quatro ou mais vezes com seus respectivos padrinhos ou madrinhas.

Além do contato presencial surgiram outras formas de contato entre o aluno ingressante e o seu respectivo padrinho ou madrinha, sendo que em $75 \%$ dos casos tal interação se deu através do uso de redes sociais (Facebook, WhatsApp e e-mails).

O questionário aplicado contemplava outros elementos que se voltavam para a situação do discente dentro do curso em que havia ingressado. Nesse sentido, a atual estrutura curricular integra um elenco de sete disciplinas obrigatórias no primeiro semestre. Perguntamos aos alunos se haviam conseguido concluir todas as disciplinas, independente de haverem sido aprovados. Em relação a essa questão, 35\% responderam que sim e $65 \%$ responderam que não. Ou seja, quase $2 / 3$ dos ingressantes no primeiro semestre não conseguiram concluir as sete disciplinas obrigatórias. Todos os casos de não-conclusão indicaram a disciplina de Cálculo I como responsável pelo fato, seja sozinha ou acompanhada de outras disciplinas.

Avaliar o próprio desempenho nos pareceu uma forma de colocar os discentes diante de um exercício interessante, não somente em termos de produzir uma reflexão sobre si mesmos, mas de contribuir a um processo geral de amadurecimento onde uma das principais etapas se desenvolve justamente a partir do ingresso na universidade. Os dados da Tabela 1 são interessantes, em primeiro lugar, porque nenhum discente se negou a informar como enxerga $o$ próprio desempenho ou performance.

O desempenho regular (60\%) se mostra associado, em grande medida, à questão anterior na medida em que uma parcela substancial dos respondentes não conseguiu satisfazer plenamente o grau de aprovação que se espera no elenco de disciplinas que integram o primeiro semestre do curso de Zootecnia. Por fim, a proporção dos que atribuem a si um desempenho 
plenamente satisfatório (5\%) é claramente superada pelo grupo de performance insatisfatória (10\%). Visto sob esse prisma os discentes mostraram maturidade ao dar suas respostas.

Tabela.1 Distribuição dos entrevistados em relação à avaliação do próprio desempenho desde o ingresso no curso de Zootecnia

\begin{tabular}{lc}
\hline Auto avaliação & Percentual (\%) \\
\hline Plenamente satisfatório & 5,0 \\
Satisfatório & 25,0 \\
Regular & 60,0 \\
Insatisfatório & 10,0 \\
\hline Total & 100,0 \\
\hline \multicolumn{2}{c}{ Fonte: Pesquisa de campo (2019). }
\end{tabular}

As taxas de evasão são altas no curso de Zootecnia. Em relação a esse assunto, indagamos aos alunos entrevistados se pretendiam seguir frequentando o curso. Uma esmagadora maioria (85\%) respondeu afirmativamente, ao passo que $10 \%$ disseram que não e $5 \%$ não sabem ou não quiseram responder. Perguntamos aos discentes se dentro de seu modo de ver as coisas, iniciativas como o projeto Tutorias na FAEM trazia benefícios para os alunos ingressantes no curso de Zootecnia. A proporção dos que responderam sim alcançou $85 \%$, enquanto que $10 \%$ disseram não e $5 \%$ não souberam ou não quiseram opinar.

Pedimos aos discentes que livremente indicassem quais seriam os benefícios efetivos do projeto Tutorias. As respostas foram bastante variadas, mas um dos aspectos mais destacados é o de propiciar ao discente informações claras sobre o curso de Zootecnia e a faculdade (FAEM), familiarizando-os dentro de uma nova realidade. Isso inclui conhecer os grupos de pesquisa existentes e ajudar o aluno a se integrar na comunidade. Um dos alunos foi categórico ao reiterar que:

O professor tutor é o que mais me ajudou no curso, pois ele conhece grande parte das dificuldades que enfrentamos, sabe nos dizer como os grupos funcionam, seus lados positivos e negativos, como podemos nos sair melhor. Já meu primeiro padrinho nos cedeu alguns materiais, mas nada além disso e a madrinha, atualmente, apesar de ser muito legal, também não a vejo muito e converso muito pouco, nos reunimos informalmente uma vez.

No tópico relativo à identificação das virtudes de um bom professor tutor as opiniões se dividem entre aqueles que teceram elogios aos mestres e os que criticaram abertamente docentes que não se mostraram dispostos a se reunir com seus tutorados. Em geral referem-se ao caso dos que tiveram um único encontro, como aludimos anteriormente. No conjunto de depoimentos colhidos, apenas $25 \%$ manifestaram não saber indicar sugestões de melhoria do projeto. Os $75 \%$ restante indicaram várias formas de aperfeiçoamento. No grupo que efetivamente indicou pontos de mudança, $60 \%$ apontaram que se deveria ter um maior rigor na escolha de docentes tutores e alunos padrinhos e madrinhas. Os dois depoimentos que a seguir transcrevemos sintetizam a posição desses alunos:

O projeto é uma ideia muito boa, porém na prática deixa algumas falhas, nem todos os professores e padrinhos se dispõem aos alunos. Acho que este é o único ponto que deixa a desejar.

Deve-se conversar bem com os tutores e padrinhos antes de colocarem eles nesse projeto, pois muitas vezes, como foi meu caso, o aluno acaba ficando desamparado e tendo que correr por conta própria, enquanto seus outros colegas não.

As sugestões de aperfeiçoamento refletem avaliações peculiares, como no sentido de apontar a necessidade de se auxiliar os alunos no campo pedagógico, particularmente no que 
tange ao processo ensino-aprendizagem. Isso é crucial, sobretudo diante das dificuldades que conspiram para as altas taxas de reprovação dos alunos. O depoimento de um dos entrevistados ilustra com clareza essa dinâmica: "[...]o projeto pode voltar mais para algumas táticas de estudo, pois a maioria da reprovação nas disciplinas pode ser por não se saber estudar".

Embora a ideia geral haja indicado um forte destaque para o papel dos alunos veteranos (padrinhos e madrinhas) no processo de aclimatação dos calouros, compartilhamento de informações e apoio em geral, há também sugestões importantes, como assim revela um dos entrevistados:

Que os padrinhos tenham um horário para falar com os "afilhados" [sic], nem que seja 30 min ao meio dia ou no RU [restaurante universitário] mesmo ou no whats [sic] ou por e-mail, mas que se mostrem mais interessados em nos ajudar, em conversar, porque nem sempre temos tempo de dar mil explicações e entendo que às vezes eles também possuem coisas para fazer, mas então qual seria o papel do padrinho? Para mim só o professor tutor me ajuda, em muito mais coisas, do que minha madrinha.

A avaliação geral do projeto é francamente positiva. Os discentes reconhecem o esforço envidado pelos atores envolvidos (docentes, madrinhas, padrinhos, servidores técnicoadministrativos) e pela própria administração central que realizou inclusive um evento exclusivo para tratar da questão da evasão. Do ponto de vista do alunado resta o reconhecimento de que o projeto é recente e merece ser aperfeiçoado. As críticas que surgiram a partir da realização dessa pesquisa servem para qualificar o processo que pode inclusive servir como um marco de referência para que experiências similares possam surgir em outras instituições de ensino superior, sejam elas de natureza pública ou privada.

\section{CONSIDERAÇÕES FINAIS}

O sistema de ensino superior no Brasil se ampliou e se complexificou ao longo das três últimas décadas. As grandes tendências foram desenhadas, a grandes traços, na parte inicial desse artigo. Há uma ingente produção acadêmica e científica voltada ao estudo das causas que conspiram para que esse problema adquira a atual dimensão. Nesse artigo o foco recaiu não exatamente em discutir os fatores que engendram a evasão ou em dissecar o repertório de causas que, em maior ou menor medida, explicam a sua persistência. A ênfase voltou-se no sentido de revelar as razões que explicam a criação de um projeto voltado a combater o fenômeno da evasão estudantil dentro de um curso específico onde esse problema assume proporções inquietantes.

Diante desse cenário ações efetivas são importantes, mesmo que limitadas no tempo e no espaço. Com efeito, não se trata aqui de buscar uma avaliação a partir do prisma de quem esteve à frente do processo, mas de situar a questão do ponto de vista dos indivíduos para os quais as ações foram concebidas. Nesse contexto, estabelecer uma atmosfera de compromisso, solidariedade e acolhimento nos parece uma atitude tão revolucionária quanto ampliar o acesso à universidade para as classes desfavorecidas e para quem nossas portas invariavelmente estiveram fechadas.

Numa obra seminal Freire $(1987$, p. 78$)$ vaticinou: "não é no silêncio que os homens se fazem, mas na palavra, no trabalho, na ação-reflexão". Frente ao célebre aforismo enunciado pelo patrono da educação brasileira fica a certeza de que há muito a se construir e apreender na vida universitária. Nesse contexto, se as reflexões aqui reunidas servirem de base para estimular novos trabalhos e avançar na interlocução acerca das causas da evasão e das formas de enfrentamento a essa mazela nacional, damos por sentados os pressupostos que motivaram a realização da pesquisa e o artigo que expõe os seus principais resultados. 


\section{Agradecimentos}

Este artigo foi concebido durante missões científicas realizadas entre os meses de agosto de 2019 e setembro de 2020 por ambos os autores junto ao "Instituto de Estudios Sociales Avanzados" (IESA) de Córdoba, Andaluzia, Espanha, dentro do marco do Programa CAPESPRINT-UFPel. No caso do primeiro autor, mediante a concessão de bolsa de Professor Visitante Júnior (Processo no 88887.363881/2019-00) e de bolsa de Professor Visitante Sênior (Proceso $n^{o}$ 88887.363956/2019-00) ao segundo autor. Expressam eles sua gratidão a CAPES e também ao IESA pelo acolhimento, sem o qual tais missões não teriam sido possíveis.

\section{REFERÊNCIAS}

ANDRIOLA, Wagner Bandeira; ANDRIOLA, Cristiany Gomes; MOURA, Cristiane Pascoal. Opiniões de docentes e de coordenadores acerca do fenômeno da evasão discente dos cursos de graduação da Universidade Federal do Ceará (UFC). Ensaio, Rio de Janeiro, v. 14, n. 52, p. 365-382, 2006.

BAGGI, Cristiane Aparecida dos Santos; LOPES, Doraci Alves. Evasão e avaliação institucional no ensino superior: uma discussão bibliográfica. Avaliação (Campinas) [online], Sorocaba, v. 16, n. 2, p. 355-374, 2011.

BRASIL. Ministério da Educação. Secretaria de Educação Superior. Comissão Especial de Estudos sobre a Evasão nas Universidades Públicas Brasileiras. Diplomação, retenção e evasão nos cursos de graduação em instituições de ensino superior públicas. Brasília: MEC, 1997. Disponível em: http://www1.udesc.br/arquivos/id_submenu/102/diplomacao.pdf. Acesso em: 17 nov. 2019.

BRASIL. Ministério da Educação. Portaria Normativa nº 39, de 12 de dezembro de 2007. Institui o Programa Nacional de Assistência Estudantil - PNAES. Diário Oficial da União, Brasília, 13 dez. 2007. Seção 1, p. 39.

BRASIL. Presidência da República. Decreto no 7.234, de 19 de julho de 2010. Dispõe sobre o Programa Nacional de Assistência Estudantil - PNAES. Diário Oficial da União, Brasília, 20 jul. 2010. Seção 1, p. 5.

BRASIL. Instituto Brasileiro de Geografia e Estatística. Pesquisa Nacional por Amostra de Domicílios Contínua - PNAD Contínua. Brasília, 2020. Disponível em: https://www.ibge.gov.br/estatisticas/sociais/populacao/9173-pesquisa-nacional-por-amostra-dedomicilios-continua-trimestral.html?t=destaques $>$

CUNHA, Simone Miguez; CARRILHO, Denise Madruga. O processo de adaptação ao ensino superior e o rendimento acadêmico. Psicologia Escolar e Educacional, Maringá, v. 9, n. 2, p. 215-224, 2005.

DAVOK, Delsi Fries; BERNANRD, Rosilane Pontes. Avaliação dos Índices de Evasão nos Cursos de Graduação da Universidade do Estado de Santa Catarina - UDESC. Avaliação (Campinas) [online], Sorocaba, vol.21, n.2, p.503-522, 2016.

DIOGO, Maria Fernanda Diogo; RAYMUNDO, Luana dos Santos; WILHEIM, Fernanda Ax; ANDRADE, Sílvia Patrícia Cavalheiro; LORENZO, Flora Moura; ROST, Flávia Trento; BARDAGI, Patta Bardagi. Percepções de coordenadores de curso superior sobre evasão, reprovações e estratégias preventivas. Avaliação (Campinas) [online], Sorocaba, v. 21, p. 125-151, 2016. 
EUROSTAT. Statistics Explained. Statistics on young people neither in employment nor in education or training. Disponível em: <https://ec.europa.eu/eurostat/statisticsexplained/index.php?title=Statistics_on_young_people_neither_in_employment_nor_in_educ ation_or_training>. Acesso em 19 set. 2020.

FREIRE, Paulo. Pedagogia do Oprimido, Rio de Janeiro: Paz e Terra, 1987.

GIL, Antônio Carlos. Métodos e técnicas da pesquisa social. 5. ed. São Paulo: Atlas, 2007.

LOBO, Maria Beatriz de Carvalho Melo. Panorama da evasão no ensino superior brasileiro: aspectos gerais das causas e soluções. In: Instituto Lobo para Desenvolvimento da

Educação, da Ciência e da Tecnologia (Org.). Instituto Lobo. São Paulo, 2012. Disponível em: <https://www.institutolobo.org.br/core/uploads/artigos/art_087.pdf>. Acesso em: 20 set. 2020 .

LOBO, Roberto; HIPOLITO, O.; MOTEJUNAS, P. R.; LOBO, M. B. C. M. A Evasão no Ensino Superior Brasileiro. Cadernos de Pesquisa [Fundação Carlos Chagas. Impresso], v. 37, p. 641-659, 2007.

IBGE, Instituto Brasileiro de Geografia e Estatística. Censo Demográfico 2010. Disponível em: https://www.ibge.gov.br/estatisticas/sociais/educacao/9662-censo-demografico2010.html?t=downloads. Acesso em: 13 set. 2020

IBGE, Instituto Brasileiro de Geografia e Estatística. Pesquisa Nacional por Amostra de Domicílios Contínua 2018. Disponível em:

https://www.ibge.gov.br/estatisticas/sociais/trabalho/17270-pnad-

continua.html?edicao $=24772 \& \mathrm{t}=$ resultados. Acesso em: 17 set. 2020

SAMPAIO, Breno; SAMPAIO, Yony; MELLO, Euler de; MELO, Andrea. Desempenho no vestibular, background familiar e evasão: evidências da Universidade Federal de Pernambuco. In: Encontro Regional de Economia, 15., 2011. Anais... 2011. Disponível em:

$<$ http://www.bnb. gov.br/content/aplicacao/eventos/forumbnb2010/docs/desempenhonovestibular.pdf>. Acesso em: 01 dez. 2019.

SCALI, Danyelle Freitas. Evasão nos Cursos Superiores de Tecnologia: a Percepção dos Estudantes sobre seus Determinantes. 2009.140 f. Dissertação (Mestrado em Educação) Faculdade de Educação. São Paulo: Universidade Estadual de Campinas, 2009.

VANZ, Samile Andrea de Souza; PEREIRA, Patrícia Mallmann Souto; FERREIRA, Glória Isabel Sattamini; MACHADO, Geraldo Ribas. Evasão e retenção no curso de Biblioteconomia da UFRGS. Avaliação, (Campinas) [online], Sorocaba, v. 21, n. 2, p. 541-568, 2016.

VELLOSO, Jacques; CARDOSO, Claudete Batista. Evasão na educação superior: alunos cotistas e não-cotistas na Universidade de Brasília. In: REUNIÃO ANUAL DA ANPEd, 31., 2008, Caxambú. Anais... Associação Nacional de Pós-Graduação e Pesquisa em Educação.

Recebido: $25 / 10 / 2020$

Aceito: 13/06/2021

Publicado: Agosto de 2021 